Stereotactic

and Functional

Neurosurgery
Stereotact Funct Neurosurg 2015;93:102-109

DOI: $10.1159 / 000367665$
Received: March 24, 2014

Accepted after revision: August 18, 2014

Published online: February 18, 2015

\title{
The Relation between Catheter Occlusion and Backflow during Intraparenchymal Cerebral Infusions
}

\author{
Martin L. Brady ${ }^{\mathrm{a}}$ Raghu Raghavan ${ }^{\mathrm{a}}$ Walter Block ${ }^{\mathrm{b}, \mathrm{c}}$ Benjamin Grabow ${ }^{\mathrm{c}}$ \\ Chris Ross $^{g}$ Ken Kubota $^{h}$ Andrew L. Alexander ${ }^{b, d, e}$ Marina E. Emborg ${ }^{b, f}$ \\ aTherataxis, LLC, Baltimore, Md., Departments of ${ }^{\mathrm{b}}$ Medical Physics, ${ }^{\mathrm{C} B i o e n g e n e e r i n g ~ a n d ~}{ }^{\mathrm{d}}$ Psychiatry, ${ }^{\mathrm{e}}$ Waisman \\ Laboratory for Brain Imaging and Behavior and fPreclinical Parkinson's Research Program, Wisconsin National \\ Primate Research Center, University of Wisconsin, Madison, Wisc., ${ }^{9}$ Engineering Resources Group, Inc., Pembroke \\ Pines, Fla., and hinetics Foundation, Los Altos, Calif., USA
}

\section{Key Words}

Convection-enhanced delivery · Backflow .

Intraparenchymal infusion - Magnetic resonance

imaging $\cdot$ Parkinson's disease

\begin{abstract}
Background/Aims: The distribution of infusate into the brain by convection-enhanced delivery can be affected by backflow along the catheter shaft. This work assesses the following: (1) whether tissue coring and occlusion of the catheter lumen occurs when an open end-port catheter is inserted, (2) whether there is a relationship between intracatheter pressure and backflow, and (3) whether catheter occlusion increases backflow. Methods: Freshly excised monkey brains were used to assess tissue coring and its correlation with the behavior of the line pressure. In vivo infusions of gadolinium solution into monkey putamen at $1 \mu \mathrm{l} / \mathrm{min}$ were conducted with and without a stylet during insertion. The effect of flow during insertion was evaluated in vivo in the pig thalamus. $\mathrm{MRI}$ and line pressure were continuously monitored during in vivo infusions. Results: Ex vivo testing showed that open end-port insertions always cored tissue (which temporarily plugs the catheter tip) and increased pressure followed by a rapid fall after its expulsion. Catheter insertion with a stylet
\end{abstract}

(c) 2015 S. Karger AG, Basel

$1011-6125 / 15 / 0932-0102 \$ 39.50 / 0$ in place prevented coring but not flow insertion; neither affected backflow. Conclusion: Open end-port catheters occlude during insertion, which can be prevented by temporarily closing the port with a stylet but not by infusing while inserting. Backflow was not completely prevented by any insertion method.

(c) 2015 S. Karger AG, Basel

\section{Introduction}

For close to two decades now, the targeted delivery of therapeutics directly into the brain - often employing convection-enhanced delivery [1] - has been used in clinical trials for the treatment of brain cancer $[2,3]$ as well as neurodegenerative diseases [4-6]. Backflow, the preferential reflux of infusate along the catheter shaft, is one of several factors that affect the efficient delivery of therapeutics to a desired target within the brain $[7,8]$. Backflow is observed both during the direct injection of a bolus such as reported in [9] or [10] - and with convection-enhanced delivery, where the infusion is at a relatively low flow rate (less than $1 \mathrm{ml} / \mathrm{h}$ ) and is continued for a longer time (tens of minutes to hours [11,12]). Targeted delivery into the putamen is particularly sensitive to backflow loss.

\section{KARGER 125}

E-Mail karger@karger.com

www.karger.com/sfn
Martin Brady

Therataxis, LLC

1101 E. 33rd Street, Ste. B305

Baltimore, MD 21218 (USA)

E-Mail mbrady@therataxis.com 
The putamen is a narrow structure and is surrounded by white matter tracts that have high fluid conductivity. If these tracts are reached by backflow, the infusate tends to flow into them, leaving a reduced fraction of infusate in the putamen [13]. Thus, backflow is of considerable concern in intraputamenal infusions.

The dominant theory in the infusion field is that tissue cored during catheter insertion acts as a plug at the start of infusion, which results in a buildup of intraline pressure until the tissue is expelled [1]. This is then followed by the sudden flow of infusate accompanied by a drop in pressure and then increased backflow. However, one study failed to find tissue in the needle upon insertion [14], and other reasons have been suggested for a drop in pressure such as a bubble in the line which is expelled [15]. An open end-port catheter is most likely to core tissue during insertion; therefore, strategies aiming to overcome this possibility have been proposed. The end port can be closed during insertion by inserting a tight-fitting stylet or by using a closed-end configuration [16]. Flow insertion, in which the catheter is inserted while infusing, is proposed to resist the tissue core [17-19]. Interestingly, these reports do not demonstrate tissue coring during insertion. Furthermore, publications documenting changes in infusion line pressure using different methods of insertion are not currently available.

In this study, we used ex vivo and in vivo methods to evaluate whether different insertion methods (open end port, closed end port and flow insertion) affected tissue coring and catheter occlusion. We evaluated changes in line pressure as a surrogate marker to assess catheter occlusion and clearance and its relationship with the incidence and magnitude of backflow.

\section{Materials and Methods}

\section{Infusion System}

A valve tip (VT) catheter with a retractable stylet was used in this study. The VT catheter (Engineering Resources Group, Inc., Pembroke Pines, Fla., USA) is a modified open end-port stepped catheter with a fused silica shaft of $0.65-\mathrm{mm}$ outer diameter and a polyimide tip with an outer diameter of $0.36 \mathrm{~mm}$ and an inner diameter of $0.25 \mathrm{~mm}$ extending $3 \mathrm{~mm}$ from the shaft. The catheter includes a silica stylet that can be extended approximately $1 \mathrm{~mm}$ beyond the end to close the end port during insertion and then retracted $8-10 \mathrm{~mm}$ prior to infusion. The catheter was also used to test open end-port and flow insertion by leaving the stylet retracted throughout the procedure. We note that the catheter itself is rigid, and in vivo imaging showed similar accuracy with or without the stylet, with no discernible deformation. The only purpose of the stylet in these studies was to obstruct the lumen of the catheter, preventing coring. This was confirmed indirectly in vivo by the absence of the characteristic behavior of the pressure when coring occurs.

Thick-walled Teflon lines with an inner diameter of $500 \mu \mathrm{m}$ were used to connect the catheter to 5-ml Hamilton gas-tight syringes. The syringes were driven by a magnetic resonance imaging (MRI)-compatible syringe pump (PHD 2000; Harvard Apparatus, Inc., Holliston, Mass., USA) placed at approximately the same height as the catheter tip when inserted.

\section{Pressure Measurement}

Monitoring of the pressure of the infusion lines was performed using a pressure monitor and pump controller (Engineering Resources Group, Inc.). This PC-based system was used remotely from the MRI control room. Infusion line pressure was acquired at 1-second intervals. Peak pressure was recorded as the single highest 1-second measurement obtained near the start of the infusion. The term pressure drop was defined as the difference between the peak pressure and the mean of the pressure measured from 10 to $30 \mathrm{~s}$ after the peak.

\section{Magnetic Resonance Imaging}

Imaging was performed in a 3-tesla GE MR 750 Discovery MRI scanner (GE Healthcare, Waukesha, Wis., USA) as previously described [16]. A custom 3-inch diameter, receive-only surface coil (MR Instruments, Inc., Minneapolis, Minn., USA) was used for scanning.

\section{Backflow Measurement}

Backflow distances of infusate, doped with common T1-shortening agents, were measured using the first T1-weighted scan, which was acquired 3-10 min after the start of the infusion. The distance was measured from the catheter tip to the furthest extent of visible tracer along the catheter shaft using custom 3D image processing software. The distances were recorded with $0.5-\mathrm{mm}$ precision, which was limited by the resolution of the MRI.

\section{Statistical Analysis}

Backflow distances were compared using a two-sample t test, assuming equal variances, while pressure peak and drop t test comparisons used unequal variances. Two-tailed tests were used, with statistical significance defined as $\mathrm{p}<0.05$. Grouped data are presented in the test as means \pm standard deviations.

\section{Experimental Design}

Three different experimental setups were used in this project, as follows: (1) ex vivo brain tests to correlate tissue coring with inline pressure behavior, (2) in vivo brain tests to assess closed and open end-port catheter effects in line pressure and backflow, and (3) in vivo brain tests with and without flow insertion in open endport catheters to evaluate its effect in line pressure and backflow.

\section{Subjects}

All efforts were made to ameliorate the suffering of animals. This study was performed in strict accordance with the recommendations in the Guide for the Care and Use of Laboratory Animals of the National Institutes of Health. The protocol was approved by the Institutional and Animal Care Committee of the University of Wisconsin, Madison, Md. (permit No. G00554 and M02516-0-03-12).

For the first set of experiments 3 brains, 1 from a rhesus $(M a-$ caca mulatta) and 2 from cynomolgus (Macaca fascicularis) mon- 
keys, were obtained from the tissue distribution program at the Wisconsin National Primate Research Center. Immediately after euthanasia with sodium pentobarbital ( $25 \mathrm{mg} / \mathrm{kg}$, i.v. $)$ the brains were quickly removed, placed in a phosphate-buffered saline solution for transportation and used within $4 \mathrm{~h}$ post mortem.

For the second set of experiments, 4 adult female rhesus monkeys ( $M$. mulatta, 5-8 years old, $4-5 \mathrm{~kg}$ ) were used. The animals were housed individually on a 12-hour light/dark cycle and received food and water ad libitum. The animals' diet was supplemented with fruit during daily enrichment.

For the third set of experiments, 3 adolescent female pigs (Sus scrofa domesticus, 2-3 months of age, $30-35 \mathrm{~kg}$ ) were used in this study. The animals were housed individually on a 12-hour light/ dark cycle and received food and water ad libitum.

\section{Ex vivo Brain Push-Through Tests}

During testing the brains were placed in a 'doughnut'-shaped platform above a tank containing water. A solution of bromophenol blue $(0.16 \mathrm{mg} / \mathrm{ml}$; Sigma Aldrich, St. Louis, Mo., USA) in phosphate-buffered saline was infused at $1 \mu \mathrm{l} / \mathrm{min}$. Line pressure was monitored continuously and video recordings were made and synchronized with the pressure readings.

The VT catheter was used, in open or closed end-port modes, for push-through insertions and regular brain insertions targeting the putamen nucleus, with or without simultaneous infusion (flow insertion). Push-through insertions were defined as catheter insertions in the brain that followed through the tissue until the catheter emerged in the water tank. Infusion was continued until any cored tissue was expelled from the catheter tip and dye was observed in the water.

\section{In vivo Open and Closed End-Port Tests}

Catheters were targeted using an MRI-compatible external trajectory guide (Navigus ${ }^{\mathrm{TM}}$; Medtronic Inc., Minneapolis, Minn., USA) and intraoperative MRI guidance. The surgical and targeting procedure was performed under isoflurane anesthesia following our previously published protocol [20]. The catheters were targeted to the ventral postcommissural right and left putamen, approximately 1-2 mm posterior to the coronal plane presenting the anterior commissure, and centered laterally at least $5 \mathrm{~mm}$ deep within the nucleus.

In one hemisphere the VT catheter was inserted with the stylet retracted (open end mode), exposing the open end port to tissue during insertion. In the other hemisphere a VT catheter was inserted with its stylet extending $1 \mathrm{~mm}$ past the distal end, covering the end port. After insertion, the stylet was retracted $8-10 \mathrm{~mm}$ in order to open the end port for infusion. A solution of gadoteridol ( $2 \mathrm{mmol} / \mathrm{l}$, ProHance; Bracco Diagnostics Inc., Princeton, N.J., USA) and bromophenol blue $(0.16 \mathrm{mg} / \mathrm{ml}$; Sigma Aldrich) in phosphate-buffered saline was infused at a flow rate of $1.0 \mu \mathrm{l} / \mathrm{min}$. A volume of $100 \mu \mathrm{l}$ was infused in each infusion.

Imaging with a pair of 3D spoiled gradient echo scans with flip angles of 6 and $34^{\circ}$ allowed quantitative measurement of the infusate distribution $(\mathrm{TR}=21 \mathrm{~ms}, \mathrm{TE}=6 \mathrm{~ms}$, in-plane $\mathrm{FOV}=140 \times$ $105 \mathrm{~mm}(0.75$ phase FOV $)$, matrix $=256 \times 224,64$ contiguous cor onal slices each $0.8 \mathrm{~mm}$ thick). Scans were acquired at intervals of approximately $10 \mathrm{~min}$ per pair.

\section{In vivo Flow Insertion Tests}

Catheters were targeted using an MRI-compatible external trajectory guide (Navigus; Medtronic Inc.) and a novel, real-time intraoperative guidance system $[21,22]$, following a modified pub- lished protocol [20]. The animals were fasted for $12 \mathrm{~h}$ prior to the surgery. Anesthesia was induced using intramuscular injections of Telazol (7 mg/kg), xylazine $(2.2 \mathrm{mg} / \mathrm{kg})$ and atropine $(0.05 \mathrm{mg} / \mathrm{kg})$ and then maintained with inhaled isoflurane. The planned trajectories were targeted either laterally centered at the rostral end or caudally/rostrally centered at the lateral side of the thalamus and at least $5 \mathrm{~mm}$ deep into the nucleus. A preoperative T1-weighted MRI was used as a roadmap to identify trajectories that were then confirmed using real-time MRI guidance. The animal was then moved from the MRI scanner room to an adjacent operating room where two bilateral craniotomies ( $5 \mathrm{~mm}$ in diameter) $20 \mathrm{~mm}$ right and left from the midline point were performed using a burr drill. A Navigus base and MR-visible trajectory guide were centered over each craniotomy. Target and device pivot locations were again identified using a T1-weighted MRI roadmap. The MR-visible trajectory guide was adjusted to the correct location using real-time MRI guidance. The trajectory guide was then removed and replaced with a remote introducer, which was then used to insert the infusion catheter to the prescribed depth, as previously described [20].

VT catheters in the open end-port mode (stylet retracted) were used. A solution of gadodiamide $(2 \mathrm{mmol} / \mathrm{l}$, Omniscan; GE Healthcare $)$ and bromophenol blue $(0.16 \mathrm{mg} / \mathrm{ml}$; Sigma Aldrich) in phosphate-buffered saline was infused at a flow rate of $5.0 \mu \mathrm{l} /$ min. In the flow insertion trials, the pump was started at $5.0 \mu \mathrm{l} /$ min just prior to insertion. The catheter was then advanced to the selected location in the thalamus at a rate of $5-7 \mathrm{~mm} / \mathrm{min}$. After reaching the target depth, infusion continued at the same rate of $5.0 \mu \mathrm{l} / \mathrm{min}$ for $10-15 \mathrm{~min}$. The control infusions were performed similarly, except that the pump was off during insertion and started at $5.0 \mu \mathrm{l} / \mathrm{min}$ just after insertion.

During infusion, the backflow was monitored with real-time 2D imaging. A single slice aligned with the catheter was acquired at 13 -second intervals $\left(\mathrm{TR}=33 \mathrm{~ms}, \mathrm{TE}=4.5 \mathrm{~ms}\right.$, flip angle $=50^{\circ}$, FOV $=140 \times 105 \mathrm{~mm}$, matrix $=256 \times 192$, slice thickness $=2.5 \mathrm{~mm}$ ). After each infusion, the complete infusion distribution was imaged with a $3 \mathrm{D}$ fast spoiled gradient echo scan $(\mathrm{TR}=9.1 \mathrm{~ms}, \mathrm{TE}=3.9 \mathrm{~ms}$, in-plane FOV $=180 \mathrm{~mm}$, matrix $=256 \times 224$, slice thickness $=0.8$ $\mathrm{mm}, 248$ contiguous slices spaced at $0.4-\mathrm{mm}$ intervals).

\section{Results}

\section{Open End-Port Catheters Get Occluded during Brain Insertion}

The ex vivo brain tests evaluated whether there was a relationship between catheter occlusion and clearance and the changes in infusion line pressure. A total of 7 push-through infusions were performed with open endport insertion. The results of a typical study are shown in figure 1. Figure 1c shows the pressure trace over the first $30 \mathrm{~s}$ of infusion. The differential pressure was zeroed before the start of infusion and rose roughly linearly over the first $21 \mathrm{~s}$ to a peak of $10.6 \mathrm{~mm} \mathrm{Hg}$. It then dropped sharply to a value of $-3.4 \mathrm{~mm} \mathrm{Hg}$ for the remainder of the infusion. Figure la shows an image of the catheter tip in the water bath taken from the video a few seconds before the 
Fig. 1. Tissue coring and expulsion during infusion in an open end-port catheter pushed through ex vivo brain into water below. a The catheter tip, with protruding tissue core, a few seconds before the pressure peak. b At $21 \mathrm{~s}$, the pressure falls sharply, the tissue core is expelled, and the infusate begins to flow visibly. c The infusion pressure during the first $30 \mathrm{~s}$. Pressure rises steadily for the first $21 \mathrm{~s}$, and no infusate (dye) is visible.
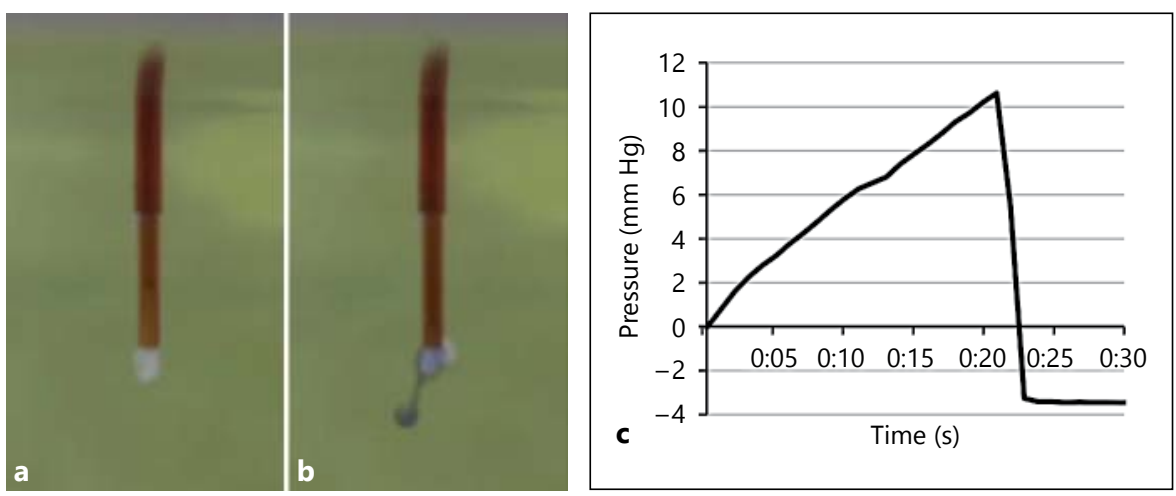

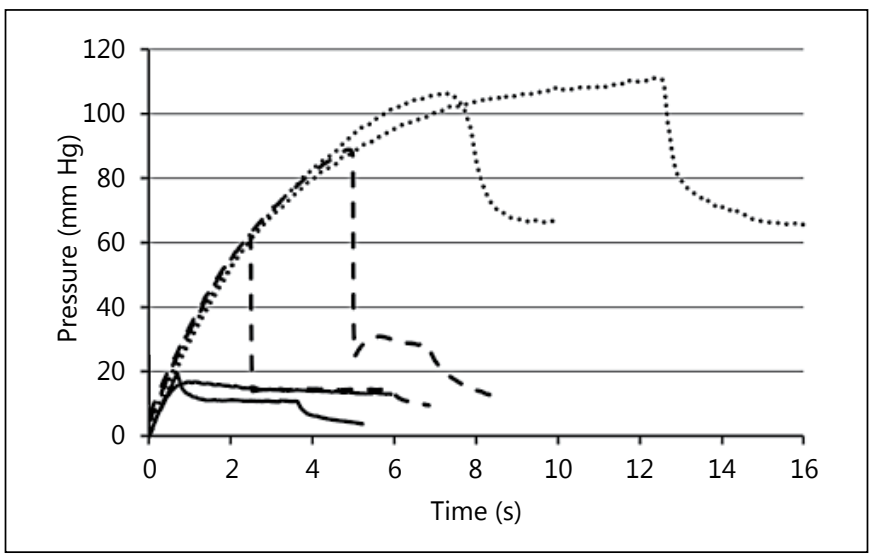

Fig. 2. Pressure plots for infusions into ex vivo monkey brain at $1 \mu \mathrm{l} / \mathrm{min}$. Solid lines represent stylet-covered insertions, dashed lines represent open end-port insertions with the pump off and dotted lines represent open end-port flow insertions.

pressure peak. Some of the cored tissue protrudes from the tip, but no infusate is observed. In figure $1 \mathrm{~b}$, a few seconds after the pressure peak, the core has been expelled and infusate flows from the tip. This pattern (pressure rise, tissue core expulsion coinciding with steep pressure drop, followed by infusate) was observed in all 7 open end-port trials (fig. 2). The mean peak pressure was $18 \pm 6 \mathrm{~mm} \mathrm{Hg}$.

Overall, 2 push-through infusions were performed with flow insertion of the open end-port VT configuration. In both cases, the pressure rose during the 20-40 s of insertion (to $19 \mathrm{~mm} \mathrm{Hg}$ in the first case and $25 \mathrm{~mm} \mathrm{Hg}$ in the second). When the catheter tip exited the tissue and entered the water bath below a tissue core was expelled, the pressure fell rapidly to about $3 \mathrm{~mm} \mathrm{Hg}$ below the preinsertion pressure and the infusate began to flow from the tip. A total of 4 push-through infusions were performed with closed end-port insertions using the VT catheter's

Catheter Occlusion in Intraparenchymal Infusions stylet. The 4 insertions did not produce an observable tissue core expulsion. The maximum pressure rise was $1.4 \mathrm{~mm} \mathrm{Hg}$, lacking the linear rise and sharp fall profile.

Additionally, insertions that stopped within the brain tissue were performed followed by infusion at $1 \mu \mathrm{l} / \mathrm{min}$ into the tissue in order to observe the pressure behavior when the tip was surrounded by tissue rather than suspended in water; 2 infusions were performed with each of the three insertion methods. Plots of the pressure for all 6 infusions are shown in figure 2. Open end-port insertions with or without flow insertion had high pressure peaks and subsequent drops. The time to reach peak pressure was much greater than in the water bath, ranging from 2.5 to $5 \mathrm{~min}$ without flow insertion and from 7.5 to $13 \mathrm{~min}$ with flow insertion. The 2 stylet-covered insertions showed much lower pressure peaks, with a small drop $(7 \mathrm{~mm} \mathrm{Hg}$ ) in the first case and no spike in the second.

\section{Backflow Does Not Differ Under Occluded versus Nonoccluded Conditions}

The in vivo open and closed end-port tests in the nonhuman primate model evaluated whether pressure changes induced by tissue coring induced affected backflow observed by intraoperative MRI. The bilateral infusions into monkey putamen were performed on 4 subjects at a flow rate of $1 \mu \mathrm{l} / \mathrm{min}$. In figure 3 , pressure traces for the first 15 min are shown for all 8 infusions. Dashed lines indicate the 4 open end-port insertions, and solid lines indicate the stylet-in-place insertions in the opposite hemispheres. The sharp pressure rise and large rapid fall were observed only for the open end-port insertions. The pressure peaks occurred within 1-3 min of the start of infusion in all but 1 case, where the pressure rise did not maintain the steep linear rise and peaked at $10.3 \mathrm{~min}$. Closed end-port infusions had a significantly lower peak pressure $(28 \pm 8 \mathrm{~mm} \mathrm{Hg})$ than the open end-port insertions $\left(73 \pm 26 \mathrm{~mm} \mathrm{Hg}^{\mathrm{t}} \mathrm{t}_{4}=\right.$ 
Fig. 3. Comparison of the pressures of infusions of $1 \mu \mathrm{l} / \mathrm{min}$ into monkey putamen with and without the use of a stylet closing the end port during insertion. Solid lines represent closed insertions and dashed lines represent open end-port insertions.
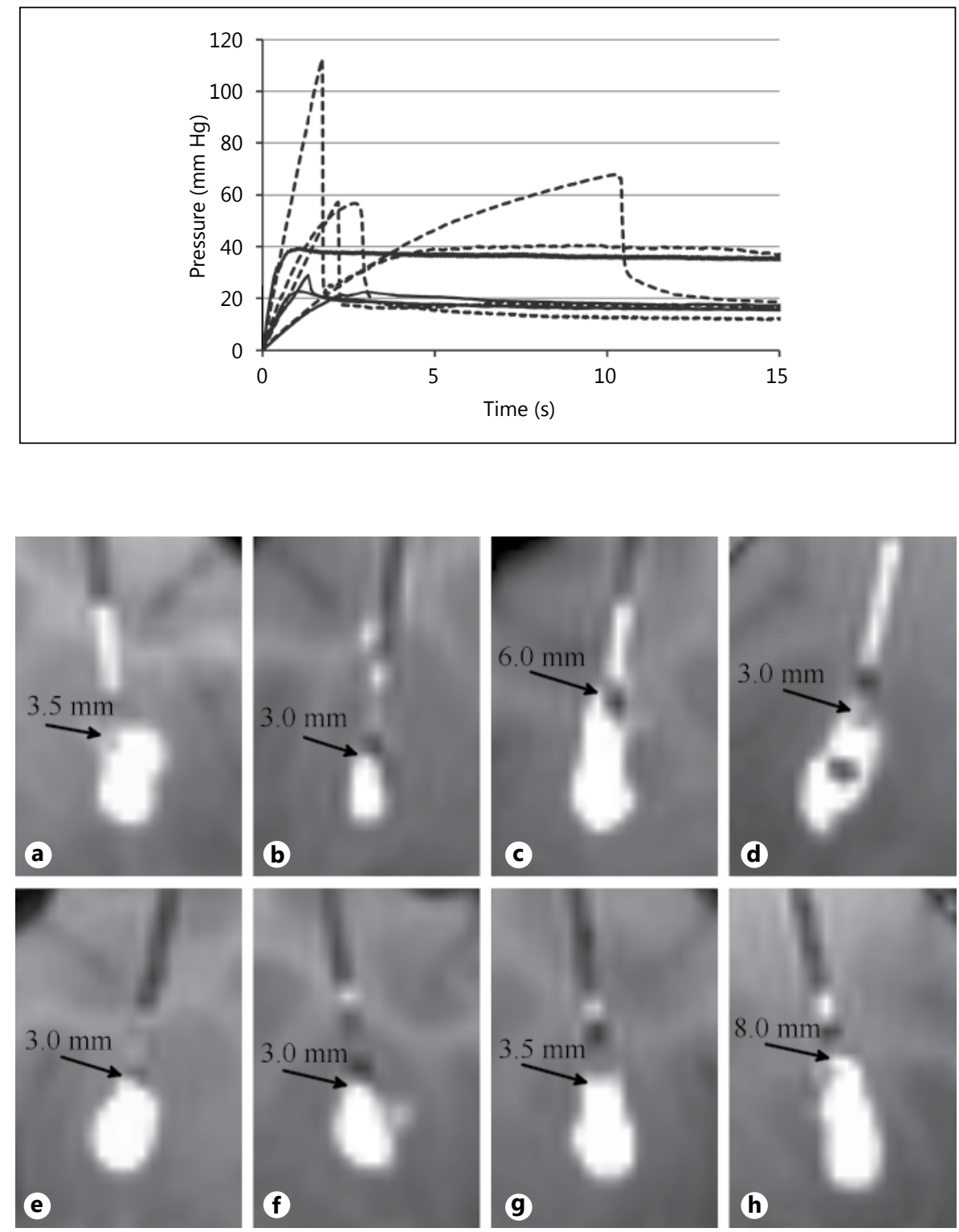

Fig. 4. Visual comparison of backflow in vivo in 4 open end-port insertions (top row) (a-d) and 4 closed end-port insertions in the contralateral hemispheres (bottom row) (e-h) in the monkey putamen. The extent of backflow in each case is indicated by an arrow.
$-3.48, \mathrm{p}=0.03)$. The pressure drop was also significantly lower for the closed end-port insertion $(3 \pm 4 \mathrm{~mm} \mathrm{Hg}) \mathrm{com}$ pared to the open one $\left(49 \pm 26 \mathrm{~mm} \mathrm{Hg}, \mathrm{t}_{3}=-3.48, \mathrm{p}=0.04\right)$.

MRIs of the catheter tips at the start of each infusion are shown in figure 4 . No deformation of the catheter was observed. Although the closed end-port insertions clearly lacked the large pressure spike that accompanied the open end-port insertions, there was no discernible reduction in backflow distance in these 4 pairs of infusions. The measured backflow with stylet-covered insertions was $4.4 \pm$ $2.4 \mathrm{~mm}$ compared to $3.9 \pm 1.9 \mathrm{~mm}$ for the open end-port control - an insignificant difference $\left(\mathrm{t}_{6}=0.35, \mathrm{p}=0.74\right)$. In figure 4 , gadolinium is visible along the catheter track of the 4 open end-port controls beyond the length of the backflow. This leakage occurs during catheter insertion without the stylet and can be observed prior to the start of infusion, which helps to distinguish it from backflow.

\section{In vivo Flow Insertion Neither Prevents Occlusion Nor}

Decreases Backflow

In vivo flow insertion tests in the swine model used changes in pressure spikes as an indirect measure of occlusions and intraoperative MRI to monitor backflow. A total of 6 infusions of each type, namely with and without flow insertion, were performed into the pig thalamus at a flow rate of $5 \mu \mathrm{l} / \mathrm{min}$. Figure 5 shows graphs of line pres- 


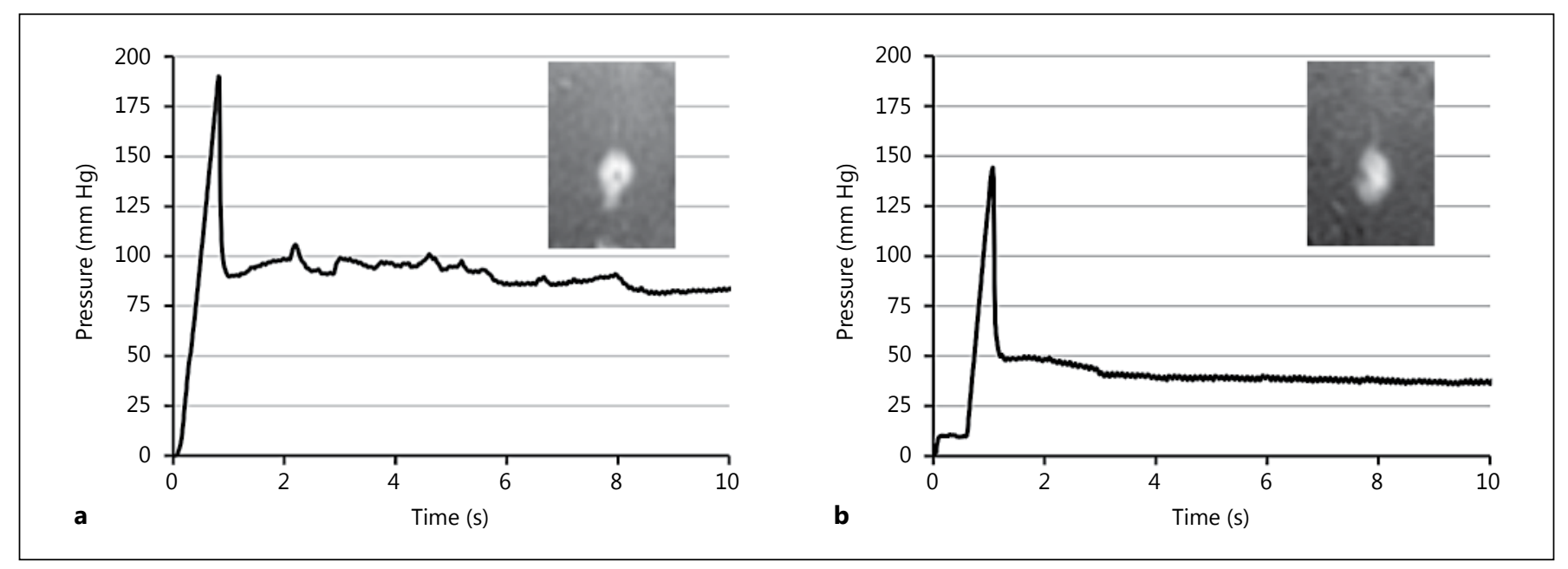

Fig. 5. Comparison of line pressure for in vivo infusions into pig thalamus at $5 \mu \mathrm{l} / \mathrm{min}$. a Standard insertion with the pump off followed by infusion at $5 \mu \mathrm{l} / \mathrm{min}$. b Flow insertion and subsequent infusion at $5 \mu \mathrm{l} / \mathrm{min}$. Insets T1-weighted real-time MRIs captured $8 \mathrm{~min}$ after the start of the infusions.

sures from a typical pair of infusions with and without flow insertion. Insets show T1-weighted real-time MRIs captured after $8 \mathrm{~min}$ of infusion. The pressure behavior appears similar in the 2 infusions, exhibiting an initial linear pressure rise and steep fall and then leveling to a relatively fixed pressure. This pressure spike behavior was observed in all 12 infusions. The peak pressure for noflow insertion ranged from $90-222 \mathrm{~mm} \mathrm{Hg}$, averaging $155 \pm 50 \mathrm{~mm} \mathrm{Hg}$. Flow insertion peak pressures averaged $149 \pm 35 \mathrm{~mm} \mathrm{Hg}$ and ranged from 84 to $189 \mathrm{~mm} \mathrm{Hg}$. The size of the post-peak pressure drop was $77 \pm 22 \mathrm{~mm} \mathrm{Hg}$ without flow insertion and $90 \pm 35 \mathrm{~mm} \mathrm{Hg}$ with flow insertion. Neither the peak nor the drop differed significantly between the two methods. A reduction in backflow with flow insertion was not observed. An analysis of the backflow in all 6 pairs of infusions shows an average backflow of $4.6 \pm 1.8 \mathrm{~mm}$ without flow insertion and $6.1 \pm 3.4$ $\mathrm{mm}$ with flow insertion. In each method, 4 of the 6 infusions had low backflow (3-5 mm), and 2 of the six had backflow greater than $5 \mathrm{~mm}$.

\section{Discussion}

In this study, as stated in Introduction, we used ex vivo and in vivo methods to evaluate whether different insertion methods (open end port, closed end port and flow insertion) affected tissue coring and catheter occlusion. The rate of $5 \mu \mathrm{l} / \mathrm{min}$ was chosen to maximize the chance of preventing coring and, in this context, the higher flow rate was appropriate. The backflow could be minimized by a lower flow rate, although coring would not have been prevented. Our paper explores the connection stated in other papers that reducing or preventing coring reduces backflow. The issue of how to reduce backflow by other means, and its effects on infusate distribution, are beyond the scope of this investigation and are described for example in a previous publication [13].

Our ex vivo and in vivo studies demonstrated the following: (1) open end-port catheters core brain tissue during insertion in accordance with conventional belief; (2) the pressure inside the infusion lines increases with occlusion and decreases when the tissue plug is released in the ex vivo tests - subsequently, we assumed that such behavior could serve to distinguish occluded tissue from freely flowing infusate; (3) a stylet prevents catheter occlusion but flow insertion does not (as evidenced by the line pressure surrogate), and (4) in controlled conditions backflow is not affected by catheter occlusion and clearance.

The ex vivo push-through experiments demonstrated that open end-port catheters tend to core several millimeters of tissue during insertion, which then occludes the catheter tip at the start of infusion. Pressure builds up within the catheter lines until the core is rapidly expelled and pressure drops suddenly. Flow insertion at $1 \mu \mathrm{l} / \mathrm{min}$ did not alter this coring and subsequent pressure spike and core expulsion. A tight-fitting stylet that covers the end port during insertion and is then withdrawn before infusion eliminated the tissue coring and the corresponding pressure spike at the start of infusion. 
It can be argued that the distance covered by the catheter in a push-through insertion is much greater than in a normal insertion, yet infusions into deep brain structures such as the subthalamic nucleus in humans can be $8 \mathrm{~cm}$ deep, as can be inferred by careful measurements during DBS placements (see table 2 of Sillay et al. [23]).

As we previously mentioned, tissue coring has been proposed for the characteristic pressure buildup and release from the very beginnings of convection-enhanced delivery application [1]. However, a subsequent study [14] failed to observe tissue coring upon insertion of the needle through ex vivo brain tissue, which is contradictory to our observations. Interestingly, that study also failed to observe any pressure rise or fall in the experiments that failed to show coring. These discrepancies suggest that differences in technical methods, including sensitivity of pressure monitoring systems and/or visualization methods, may have affected the results.

Tissue coring during in vivo intraparenchymal infusion cannot be directly confirmed, but based on our ex vivo tests the characteristic pressure spike can be used as a surrogate indicator of its presence. The ex vivo brain studies confirmed that the same pressure spike behavior is present in open end-port insertions and absent when a stylet covers the end port during insertion. The peak pressure and the duration of the pressure rise was much greater when infusing into tissue than into the water bath. We speculate that the surrounding tissue will tend to hold the cored plug in place longer than was observed in the water bath, increasing the amount of fluid collected in the line and, therefore, the pressure.

Although coring can be avoided by using a closed end port during insertion, it did not seem to have a significant impact on the infusions, as in these studies the large pressure loss on occlusion clearance did not significantly increase chances for large backflow. These experiments were also unable to demonstrate any advantage for inserting with the infusate flowing. Previous protocols have used relatively low infusion rates during insertion - up to $1 \mu \mathrm{l} / \mathrm{min}[17-19]$ - the rate at which tissue coring was observed in our ex vivo insertions. The in vivo flow insertions were performed at $5 \mu \mathrm{l} / \mathrm{min}$ in order to give the method the best chance to show an effect. In other words, we have used a higher flow rate during insertion than any reported in the literature, thus giving the best chance for the removal of occlusions. However, the pressure traces in each case showed the spike associated with occlusion and subsequent clearance (in every case performed). It is thus not surprising that, in addition, no difference in backflow was shown for flow insertion. This also suggests that ramping up to $5 \mu \mathrm{l} / \mathrm{min}$ during the insertion process would not improve the probability of expelling tissue from the catheter lumen.

The following points may be argued: (1) the number of in vivo tests comparing flow insertion to insertion without flow is too small to disprove the assertion that there is no difference in line pressure behavior or in the extent of backflow, (2) the lack of difference in tissue occlusion in such a comparison is inferred rather than demonstrated, and (3) the claim that there is no deleterious effect on backflow due to tissue occlusion is also not proven due to the small number of observations. The ex vivo studies that directly examine pressure behavior with coring of tissue resulted in a $100 \%$ correlation in 3 trials. The correlation between coring and the pressure behavior receives further support from the 4 in vivo coring tests, where preventing coring (by a blocking stylet) was shown to remove the pressure spike noted when coring occurred; conversely, when there was no blocking stylet there was indeed a pressure spike. While indirect, these results provide further evidence for the correlation directly noted in the ex vivo tests. Based on this data we conclude the following: (1) a lower flow rate upon insertion would not have prevented coring, and (2) infusing at $5 \mu \mathrm{l} / \mathrm{min}$ without ramping the flow rate (immediately upon placement) would not have lowered the backflow. Finally, although we did not observe it, tissue occlusion could possibly result in occasional 'catastrophic' backflow. Nevertheless, our failure to observe it at least indicates that backflow is not an inevitable result of having an open end-port catheter and a pressure that rises, peaks and falls abruptly after the start of the infusion.

To conclude, we have demonstrated that open endport catheters occlude during insertion, which can be prevented by temporarily closing the port with a stylet but not by infusing while inserting. Based on the present findings, the use of infusion during the insertion procedure seems unnecessary. Furthermore, its clinical translation is worrisome, especially during the infusion of biologics, for example in gene transfer, where the use of flow insertions may increase the risk of gene delivery into areas through which the catheter passes, thus increasing the risk of unwanted effects by therapy misplacement.

\section{Acknowledgments}

The investigators are grateful to Dr. K. Brunner for surgical support, Dr. E. Brodski for MRI support and V. Carter, N. Goecks, R. Velotta, J. Raschke, and D. Consigny for excellent technical assistance. 
This research was primarily supported by the Kinetics Foundation. Additional support was provided by NIH-NCRR grant P51 RR000167 (Wisconsin National Primate Research Center, University of Wisconsin) and NIH grant T32 CA009206 (University of Wisconsin). This research was conducted at a facility constructed with support from Research Facilities Improvement Program grants RR15459-01 and RR020141-01.

Finally, the authors would like to thank an anonymous referee for comments that helped to improve the presentation of the manuscript.

\section{Disclosure Statement}

All of the authors, with the exception of the last (M.E.E.), have ownership in commercial entities involved with intraparenchymal infusions. The catheter used in these studies belongs to a company owned by Chris Ross. However, none of the authors have a financial interest in the outcome of these studies. In particular, these studies did not evaluate the performance of the catheter itself but only of infusion protocols used by the community. Finally, K.K., although employed by the agency funding these studies, contributed to the discussions of the experimental designs.

\section{References}

1 Bobo RH, Laske DW, Akbasak A, Morrison PF, Dedrick RL, Oldfield EH: Convection-enhanced delivery of macromolecules in the brain. Proc Natl Acad Sci U S A 1994;91: 2076-2080

2 Kunwar S, Prados MD, Chang SM, et al: Direct intracerebral delivery of cintredekin besudotox (IL13-PE38QQR) in recurrent malignant glioma: a report by the Cintredekin Besudotox Intraparenchymal Study Group. J Clin Oncol 2007;25:837-844.

-3 Lidar Z, Mardor Y, Jonas T, Pfeffer R, Faibel M, Nass D, Hadani M, Ram Z: Convectionenhanced delivery of paclitaxel for the treatment of recurrent malignant glioma: a phase I/II clinical study. J Neurosurg 2004; 100:472479.

-4 Nutt JG, Burchiel KJ, Comella CL, Jankovic J, Lang AE, Laws ER Jr, Lozano AM, Penn RD, Simson RK Jr, Stacy M, Wooten GF: Randomized, double-blind trial of glial cell line-derived neurotrophic factor (GDNF) in PD. Neurology 2003;60:69-73.

5 Lang AE, Gill S, Patel NK, et al: Randomized controlled trial of intraputamenal glial cell line-derived neurotrophic factor infusion in Parkinson disease. Ann Neurol 2006;59:459466.

6 Marks WJ, Bartus RT, Siffert J, et al: Gene delivery of AAV2-neurturin for Parkinson's disease: a double-blind, randomized, controlled trial. Lancet Neurol 2010;9:1164-1172.

7 Morrison PF, Chen MY, Chadwick RS, Lonser RR, Oldfield EH: Focal delivery during direct infusion to brain: role of flow rate, catheter diameter, and tissue mechanics. Am J Physiol 1999;277:R1218-R1229.

8 Raghavan R, Mikaelian S, Brady M, Chen ZJ: Fluid infusions from catheters into elastic tissue. I. Azimuthally symmetric backflow in homogeneous media. Phys Med Biol 2010;55: 281-304.

9 Marks WJ, Ostrem JL, Verhagen L, Starr PA, Larson PS, Bakay RAE, Taylor R, CahnWeiner DA, Stoessl AJ, Olanow CW, Bartus RT: Safety and tolerability of intraputaminal delivery of CERE-120 (adeno-associated virus serotype 2-neurturin) to patients with idiopathic Parkinson's disease: an open-label, phase I trial. Lancet Neurol 2008;7:400-408.

10 Kaplitt M, Feigin A, Tang C, Fitzsimons H, Mattis P, Lawlor P, Bland R, Young D, Strybing K, Eidelberg D, During M: Safety and tolerability of gene therapy with an adeno-associated virus (AAV) borne GAD gene for Parkinson's disease: an open label, phase I trial. Lancet 2007;369:2097-2105.

11 Sampson J, Brady M, Petry N, Croteau D, Friedman A, Friedman H, Wong T, Bigner D, Pastan I, Puri R, Pedain C: Intracerebral infusate distribution by convection-enhanced delivery in humans with malignant gliomas: descriptive effects of target anatomy and catheter positioning. Neurosurgery 2007; 60(2 suppl 1):89-99.

12 Mehta A, Choi B, Raghavan R, Brady M, Friedman A, Bigner D, Pastan I, Sampson J: Imaging of convection-enhanced delivery of toxins in humans. Toxins 2011;3:201-206.

13 Brady ML, Raghavan R, Alexander A, Kubota K, Sillay K, Emborg ME: Pathways of infusate loss during convection-enhanced delivery into the putamen nucleus. Stereotact Funct Neurosurg 2013;91:69-78.

14 Prabhu SS, Broaddus WC, Gillies GT, Loudon WG, Chen ZJ, Smith B: Distribution of macromolecular dyes in brain using positive pressure infusion: a model for direct controlled delivery of therapeutic agents. Surg Neurol 1998;50:367-375.

15 Bauman M, Gillies G, Raghavan R, Brady MP: Physical characterization of neurocatheter performance in a brain phantom gelatin with nanoscale porosity: steady-state and oscillatory flows. Nanotechnology 2004;15:9297.

$>16$ Oh S, Odland R, Wilson S, Kroeger K, Liu C, Lowenstein P, Castro M, Hall W, Ohlfest J: Improved distribution of small molecules and viral vectors in the murine brain using a hollow fiber catheter. J Neurosurg 2007;107: 568-577.
17 Su X, Kells AP, Aguilar Salegio EA, Richardson RM, Hadaczek P, Beyer J, Bringas J, Pivirotto P, Forsayeth J, Bankiewicz KS: Real-time MR imaging with gadoteridol predicts distribution of transgenes after convection-enhanced delivery of AAV2 vectors. Mol Ther 2010;18:1490-1495.

18 Richardson RM, Kells AP, Martin AJ, Larson PS, Starr PA, Piferi PG, Bates G, Tansey L, Rosenbluth KH, Bringas JR, Berger MS, Bankiewicz KS: Novel platform for MRIguided convection-enhanced delivery of therapeutics: preclinical validation in nonhuman primate brain. Stereotact Funct Neurosurg 2011;89:141-151.

19 Yin D, Valles FE, Fiandaca MS, Bringas J, Gimenez F, Berger MS, Forsayeth J, Bankiewicz KS: Optimal region of the putamen for image-guided convection-enhanced delivery of therapeutics in human and non-human primates. Neuroimage 2011;54(suppl 1):S196S203.

20 Emborg ME, Joers V, Fisher R, Brunner K, Carter V, Ross C, Raghavan R, Brady M, Raschke J, Kubota K, Alexander A: Intraoperative intracerebral MRI-guided navigation for accurate targeting in nonhuman primates. Cell Transplant 2010;19:1587-1597.

21 Brodsky E, Block W, Alexander A, Emborg $\mathrm{M}$, Ross C, Sillay K: Intraoperative device targeting using real-time MRI. Paper presented at Biomed Sci Eng Conf, Oak Ridge, 2011.

22 Grabow B, Raghavan R, Brady M, Kubota K, Hurley S, Brodsky E, Raschke J, Alexander A, Block W: Real-time monitoring for systematic investigation of catheter design and infusion protocol effect on CED performance. $\mathrm{Pa}$ per presented at Proc ISMRM, Salt Lake City, 2013.

23 Sillay K, Kumbier L, Ross C, Brady M, Alexander A, Gupta N, Adluru N, Miranpuri G, Williams J: Perioperative brain shift and deep brain stimulating electrode deformation analysis: implications for rigid and nonrigid devices. Ann Biomed Eng 2013;41:293304 . 